\title{
MUCOID DEGENERATION OF THE ANTERIOR CRUCIATE LIGAMENT:
}

\section{A CASE REPORT}

\author{
Sonjjay Pande ${ }^{1}$, Avadhesh P. S. Kushwah ${ }^{2}$, Silas Supragya Nelson ${ }^{3}$, Atul Saxena ${ }^{4}$, Suresh Kumar ${ }^{5}$
}

\section{HOW TO CITE THIS ARTICLE:}

Sonjjay Pande, Avadhesh. P. S. Kushwah, Silas Supragya Nelson, Atul Saxena, Suresh Kumar. "Mucoid Degeneration of the Anterior Cruciate Ligament: A Case Report". Journal of Evolution of Medical and Dental Sciences 2015; Vol. 4, Issue 44, June 01; Page: 7689-7691, DOI: 10.14260/jemds/2015/1117

ABSTRACT: A case of mucoid degeneration of the anterior cruciate ligament (ACL) is reported based on specific imaging features on MRI. It is a very rare cause of knee pain and can be diagnosed preoperatively on MRI.

KEYWORDS: Mucoid Degeneration, ACL, MRI.

INTRODUCTION: CLINICAL HISTORY: A 43-years-old male patient with nonspecific left knee pain of 6 months duration. There were no clinical signs or symptoms consistent with instability. MRI of the knee was performed.

IMAGING FINDINGS: PDW fat suppressed and FSE image show diffuse increased signal along the entire course of anterior cruciate ligament. (Fig. 1) appearing indistinct on T1W images (Fig. 2).The individual fibers appeared well defined and intact on T2 (Fig. 3) and PDW SE image (Fig. 4) .These changes were consistent with diffuse ACL mucoid degeneration. Increased signal between intact, almost parallel fibers (Fig 3 and 4) bears similarity to a stalk of celery (Celery Stalk Sign"). [1] There were no secondary signs of anterior cruciate ligament injury.

DISCUSSION: Mucoid degeneration of the anterior cruciate ligament was first reported by Kumar et al in 1999.(2) Since then, there have been some cases of mucoid degeneration of the ACL reported in the English literature.(3) In many of these case reports, the presenting complaint was knee pain with a mechanical block to extend without evidence of knee instability. The pathogenesis of mucoid degeneration of the ACL is unclear, but age related degeneration. Congenital or acquired synovial tissue entrapment between ACL fiber has been implicated.(4)

Finding of mucoid degeneration of the ACL on MRI showed well-defined ACL, showing intact fibres with intervening increased signal intensity lesion on all sequences, normal orientation of the ligament, and celery-stalk appearance.(5) His appearance can mimic acute or chronic interstitial partial tears of the ligament.(4) Anterior cruciate ligament mucoid degeneration is typically not associated with ligament instability and secondary signs of anterior cruciate ligament are absent. Patients may be symptomatic or asymptomatic with Pain being a common complaint at presentation. Patients may also be unable to fully flex or extend the knee.

Either mechanical irritation due to the bulk or a chemically mediated reaction has been postulated to be a cause of pain. ${ }^{1}$ Mucinous degeneration of the anterior cruciate ligament was described as a potential pitfall for the diagnosis of a ligament tear.(6) Intraosseous ganglia, at the femoral and tibial attachments, are observed in $77 \%$ of the cases with mucoid degeneration of the ACL. $\left.{ }^{6}\right)$

Hodler et al,(7) Correlated between MRI appearance and histologic findings in cadaveric specimens, found focal areas of signal increase in 29 of 38 ligaments. In 17 of these 29 ligaments, 


\section{CASE REPORT}

mucoid and/or eosinophilic degeneration was found, which appeared to have caused the focal MRI signal change. The absence of clinical signs and symptoms consistent with instability also helps to avoid misdiagnosis. ${ }^{(1)}$

MRI is useful in preoperative diagnosis of myxoid degeneration of anterior cruciate ligament (ACL) if careful attention to clinical details and MR imaging findings of the celery stalk sign is kept in mind. This would avoid unnecessary arthroscopic intervention in asymptomatic patients.

\section{REFERENCES:}

1. Papadopoulou P (2007) Signs in Imaging: The Celery Stalk Sign Radiology 245:3 916917.doi:10.1148/radiol.2453050159.

2. Kumar A, Bickerstaff DR, Grimwood JS, Suvarna SK. Mucoid cystic degeneration of the cruciate ligament. J Bone Joint Surg. 1998; 81(2): 304-5.

3. Makoto Nishimori, Yoshio Sumen, KazukiSakaridani. Mucoid degeneration of the anterior cruciate ligament-a report of two cases. MagnReson Imaging. 2004 Nov; 22(9):1325-8.

4. Hensen J. J, Coerkamp E.G, Bloem J. L. Mucoid Degeneration of the Anterior Cruciate Ligament JBR-BTR.2007; 90: 192-193.

5. McIntyre J, Moelleken S, Tirman P. Mucoid degeneration of the anterior cruciate ligament mistaken for ligamentstears. Skeletal Radiol 2001; 30:312-5.

6. Bergin D, Morrison WB, Carrino JA, Nallamshetty SN, Bartolozzi AR. Anterior cruciate ligament ganglia and mucoid degeneration: coexistence and clinical correlation AJR. 2004; 182:12831287.

7. Hodler J, Haghighi P, Trudell D, Resnick D. The cruciate ligaments of the knee: correlation between MR appearance and Gross and histologic findings in cadaveric specimens. AJR Am JRoentgenol1992; 159:357-60.

Fig. 1: PDW Fat suppressed Sag. Image show intact but spread out fibres of ACL with intervening high signal intensity.

Fig. 2: T1 W Sagittal Image shows indistinct ACL fibres.

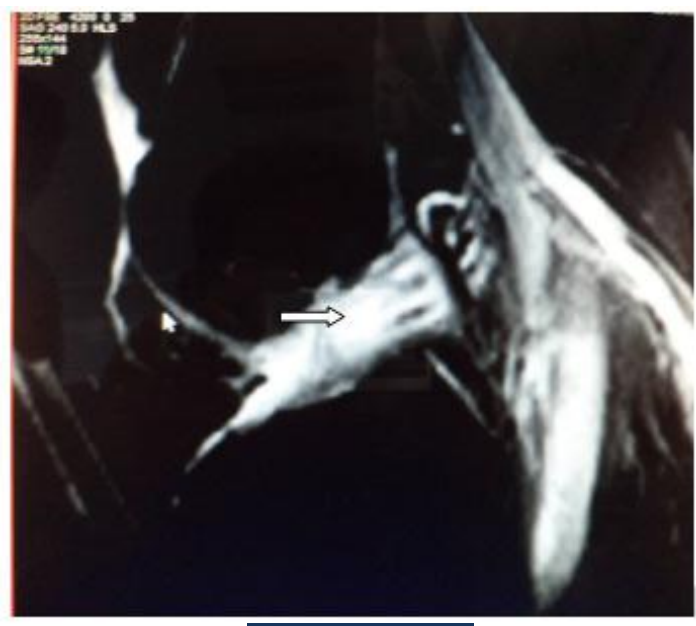

Figure 1

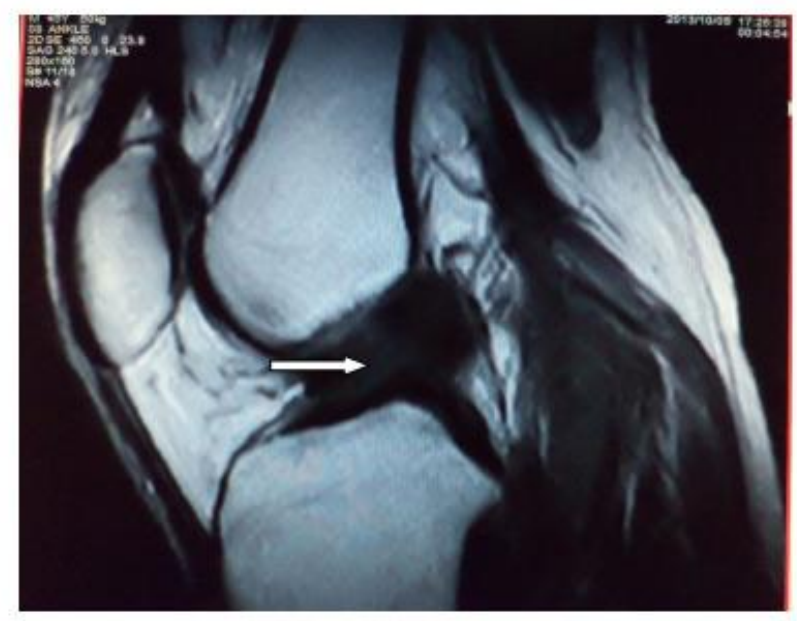

Figure 2 


\section{CASE REPORT}

Fig. 3: PD WI clearly demonstrate the intact ACL fibres.

Fig. 4: T2WI Sagittal I demonstrate intact fibres with intervening high signal intensity.

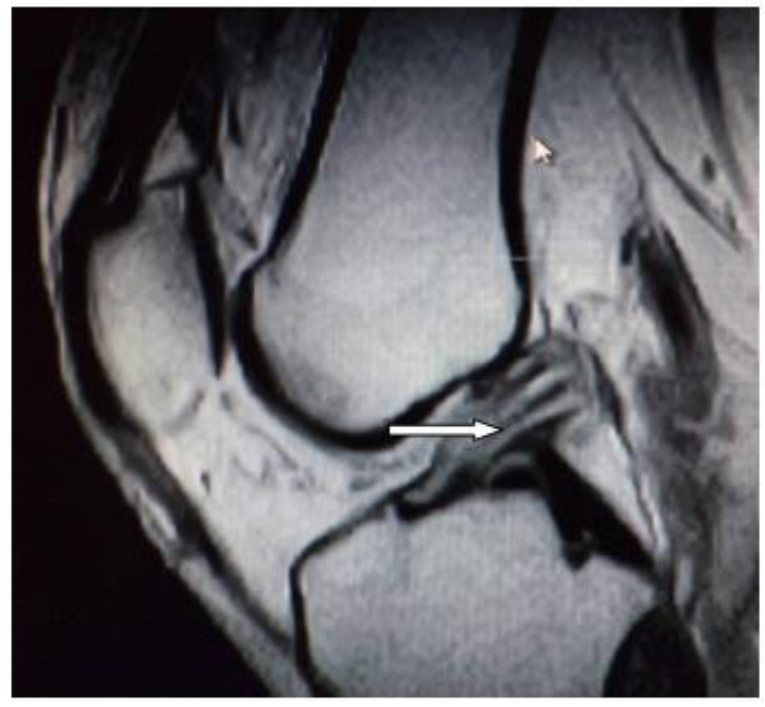

Figure 3

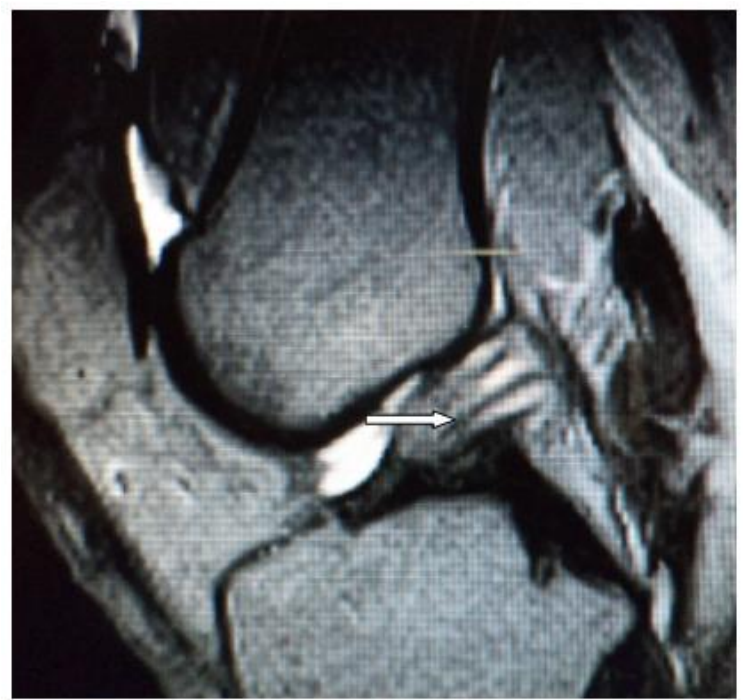

Figure 4

\section{AUTHORS: \\ 1. Sonjjay Pande \\ 2. Avadhesh. P. S. Kushwah \\ 3. Silas Supragya Nelson \\ 4. Atul Saxena \\ 5. Suresh Kumar}

\section{PARTICULARS OF CONTRIBUTORS:}

1. Associate Professor in Radio-diagnosis, NSCB Medical College, Jabalpur.

2. Assistant Professor in Radio-diagnosis, NSCB Medical College, Jabalpur.

3. Associate Professor in Medicine, NSCB Medical College, Jabalpur.

\section{FINANCIAL OR OTHER COMPETING INTERESTS: None}

\section{Professor in Radio-Diagnosis, Career} Institute of Medical Sciences, Lucknow, Uttar Pradesh, India.

5. Assistant Professor in Radio-diagnosis, NSCB Medical College, Jabalpur.

\section{NAME ADDRESS EMAIL ID OF THE CORRESPONDING AUTHOR:}

Dr. Avadhesh P. S. Kushwah,

F- 7, Doctors Colony,

Medical College Campus, Jabalpur-483002.

E-mail: kushwahavadhesh@yahoo.com

Date of Submission: 07/05/2015.

Date of Peer Review: 12/05/2015.

Date of Acceptance: 25/05/2015.

Date of Publishing: 01/06/2015. 